\title{
ARTICLE \\ Modulation of dendritic cell function by the radiation-mediated secretory protein $\gamma$-synuclein
}

\author{
S-M Kang ${ }^{1}$, M-H Kim ${ }^{1}$, K-H Song ${ }^{1}$, S-Y Jung ${ }^{1}$, J Ahn ${ }^{1}$, S-G Hwang ${ }^{1}$, J-H Lee ${ }^{2}$, D-S Lim ${ }^{2}$ and J-Y Song ${ }^{1}$
}

\begin{abstract}
Recently, $\gamma$-synuclein (SNCG), which is also known as breast cancer-specific gene-1, has been demonstrated to be an adverse and aggressive marker in breast cancer. In our previous study, SNCG was significantly upregulated in irradiated human breast cancer cells. The aim of this study was to investigate whether radiation-induced, tumor-derived SNCG can influence dendritic cell (DC) function in immune systems. The phenotypical and functional changes of DCs in the presence or absence of SNCG were investigated by FACS analysis, ELISA, and real-time PCR. The ability of SNCG-treated DCs to influence T cells was also examined by coculturing with T cells. The treatment of DCs with SNCG protein inhibited the surface expression of the co-stimulatory molecules CD40 and CD86, and decreased the mRNA levels of pro-inflammatory cytokines. The SNCG-treated DCs inhibited T-cell proliferation slightly, but distinctively increased the population of regulatory T cells. In addition, the production of TGF- $\beta$ from T cells was significantly increased when they were cocultured with SNCG-treated DCs. Taken together, these results demonstrate that tumorderived SNCG contributes to immunosuppressive effects via the inhibition of DC differentiation and activation, thus making it a potential target for cancer treatment.
\end{abstract}

Cell Death Discovery (2015) 1, e15011; doi:10.1038/cddiscovery.2015.11; published online 27 July 2015

\section{INTRODUCTION}

Radiotherapy (RT) is a well-established standard tumor treatment, and over half of all cancer patients will receive RT as part of their treatment plan. ${ }^{1,2}$ Exposure to ionizing radiation (IR) provokes several distinct cell death programs, such as apoptosis, necrosis, mitotic catastrophe, and autophagy, against tumor cells, as well as the surrounding immune cells. ${ }^{3}$ It is generally recognized that IR can cause suppressive and tolerogenic immune responses. ${ }^{4-6}$ However, an emerging body of evidence in recent years has suggested that the effects of IR on the immune system are complex. Ma et al. reported that IR induced 'danger signals' from dying tumor cells that may contribute to incite a potent antitumor immune response via immunogenic cell death (ICD) and reverting the immunosuppressive tumor microenvironment. ${ }^{7-9}$ However, the interplay between danger signaling patterns behind the trafficking of damage-associated molecular patterns (DAMPs) and their immune sensing systems appears to be very plastic and highly dependent on the dose and fractionation of radiation, the type of radiation-induced cell death, and the experimental conditions. Thus, whether the effect of intracellular proteins released by RT in cancer therapy could be beneficial or detrimental remains controversial.

We have recently demonstrated that single or fractionated doses of radiation induced several secretory proteins in human breast cancer cells. ${ }^{10}$ One of the interesting candidates from the previous study, $y$-synuclein, was markedly increased by a high single dose of $10 \mathrm{~Gy}$ but not by fractionated irradiation. The synuclein family consists of three known members, $a-, \beta-$, and $\gamma$-synuclein (SNCA, SNCB, and SNCG, respectively). They are an unfolded group of proteins that is characterized by a 5-6 repeat (KTKEGV) consensus sequence in the first 87 residues of the
$\mathrm{N}$-terminal domain, whereas their acidic C-terminal domain is considerably different, likely to distinguish their function. ${ }^{11}$ SNCA and SNCB are located in neuronal cells, especially, the substantia nigra, subthalamic nucleus, amygdala, hippocampus, and thalamus, and have relevance to neurodegenerative disorders, such as Parkinson's disease and Alzheimer's disease. ${ }^{12-14}$ However, SNCG was cloned from infiltrating breast carcinoma cells and was not closely linked to neuronal degenerative disease. ${ }^{15}$ Several studies have revealed that SNCG is highly expressed in several cancer types, such as the advanced stages of breast, liver, ovarian carcinomas, colon, and prostate cancer. ${ }^{16-20}$ SNCG was shown to promote cell growth and motility that led to cancer metastasis and invasiveness. ${ }^{21}$ In addition, the overexpression of SNCG accelerated breast and ovarian cancer development. ${ }^{17,22}$ Therefore, whether the release of dying cancer cell-derived SNCG after RT could subsequently elicit anti-tumorigenic immunity or a protumorigenic immune response remains unclear.

Dendritic cells (DCs) are distributed in epithelial tissues, including the lymphoid organs, skin, digestive, stromal and interstitial space of most parenchymatous organs. DCs play a role in immune homeostasis under physiological conditions and regulate immune activation during infection. DCs act as immune sentinels to initiate $\mathrm{T}$-cell responses against microbial pathogens or tumors or to induce self-tolerance in the immature state. ${ }^{23,24}$

The generation, maturation, and function of DCs are all markedly inhibited in cancers. Defective function of these cells is considered one of the important factors responsible for tumor escape from immune surveillance. ${ }^{25-27}$ In contrast, the presence of dying tumor cells following RT promotes DC phagocytosis of the tumor cells, the processing of tumor-derived antigens, and the enhancement of antigen presentation and cross-presentation

${ }^{1}$ Division of Radiation Cancer Sciences, Korea Institute of Radiological and Medical Sciences, Seoul 139-706, Republic of Korea and ${ }^{2}$ Department of Biotechnology, CHA University, Seongnam 463-400, Republic of Korea.

Correspondence: D-S Lim (dslim@cha.ac.kr) or J-Y Song (immu@kirams.re.kr)

Received 15 June 2015; accepted 16 June 2015; Edited by G Melino 
by DCs, resulting in a more robust adaptive immune response for anticancer activity. ${ }^{28}$ Therefore, DCs can exhibit various states and perform different functions depending on the environment they encounter. Based on the controversy regarding the effects of anticancer therapy on immune responses, the cross talk between radiation-induced changes in the tumor microenvironment and the maturation status of DCs after RT require clarification. In this study, we aim to investigate how the newly identified secretory SNCG derived from RT-treated dying tumor cells could affect DC maturation status. This study will provide clues to design a future rational and optimal regimen of RT for clinical application.

\section{RESULTS}

SNCG was increasingly secreted by breast cancer cells exposed to IR

Many studies have shown that SNCG is overexpressed in advanced infiltrating breast carcinoma. ${ }^{20}$ We also found that SNCG was increased by radiating breast cancer cells using quantitative proteomic analysis. ${ }^{10}$ Here MDA-MB231 and MCF-7 human breast carcinoma cells were exposed to single doses of 5 or $10 \mathrm{~Gy}$ of radiation and harvested at the indicated times to investigate whether SNCG expression is increased by irradiation. The SNCG expression was increased in a dose-dependent manner in MDA-MB231 cells compared with the control group at $24 \mathrm{~h}$, and the highest SNCG expression was observed at $48 \mathrm{~h}$ after irradiation with 5 Gy (Figure 1a). Similarly, the level of SNCG in MCF-7 cells was also increased by radiation and was sustained up to $72 \mathrm{~h}$ after irradiation (Figure 1b). To confirm total cancer cell death by radiation, an MTT assay was performed under the same experimental conditions as above (Figures $1 \mathrm{c}$ and $\mathrm{d}$ ). Exposure to IR significantly decreased the viability of MDA-MB231 cells in a dose- and time-dependent manner, whereas irradiation of MCF-7 cells resulted in the inhibition of cell proliferation rather than induction of cell death. Next, we investigated whether SNCG, known to be a secretory molecule, is released from irradiated breast cancer cells. As shown in Figures 1e and f, SNCG was detected in conditioned medium, thus indicating that the induction and secretion of SNCG were mediated by irradiation of human breast cancer cells. Although these data did not exactly correspond with the expression profile of SNCG, this discrepancy may be because of the different amounts generated from endogenous or exogenous origin. These findings indicate that SNCG is markedly increased and secreted from irradiated breast cancer cells.

SNCG inhibited the phenotypical maturation of bone marrow-derived DCs

The distinction between iDCs and mature DCs ( $m D C s)$ is based on phenotypical and functional changes. The enhancement of the antigen-presenting molecules MHC classes I and II along with the co-stimulatory molecules CD80 and CD86 is observed when DCs undergo maturation. ${ }^{29}$ iDCs finally differentiate into mDCs through semi-mDCs (smDCs) over time when continuously exposed to TNF- $a$ or lipopolysaccharide (LPS). Based on these studies, we investigated the phenotype of three DC subsets a

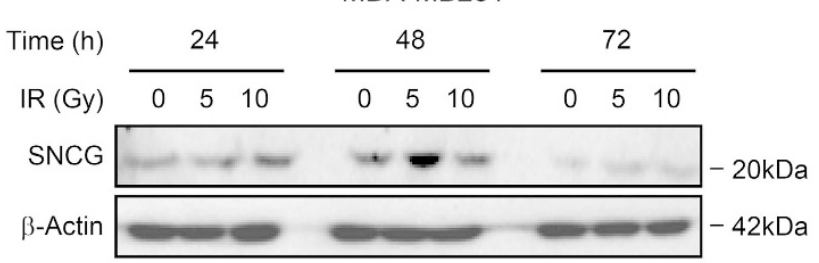

C

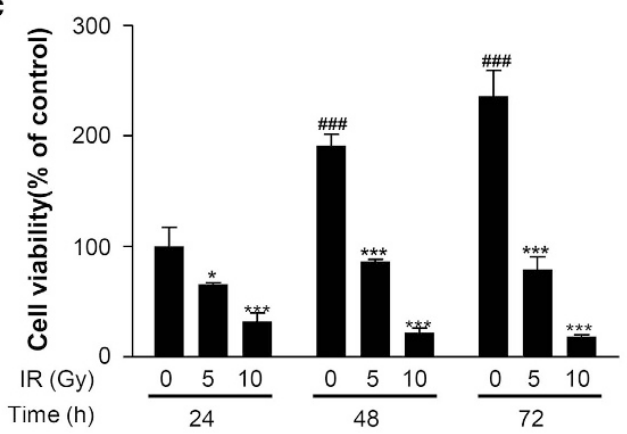

e

MDA-MB231

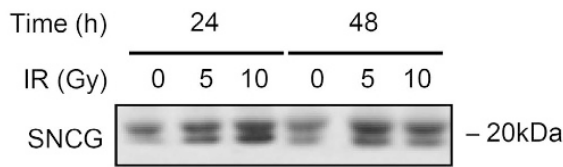

b
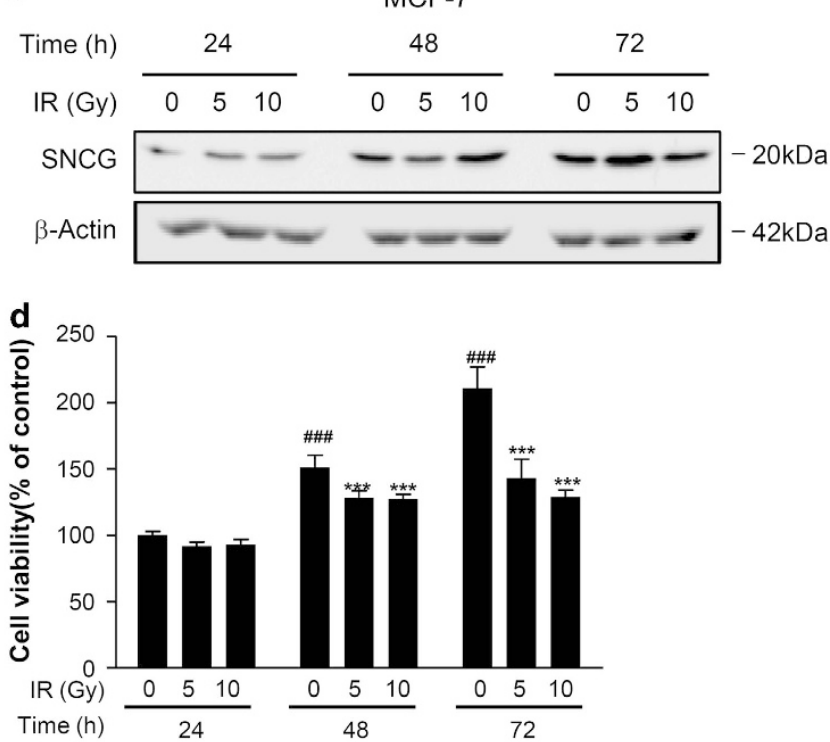

f

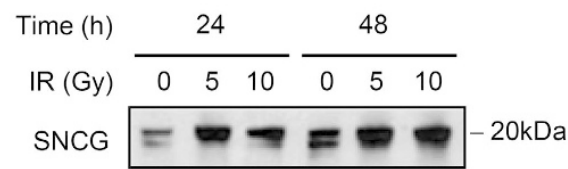

Figure 1. SNCG was increased by irradiated breast cancer cell lines. (a and b) Human breast cancer cell lines (MDA-MB231 and MCF-7) were exposed to 5 or $10 \mathrm{~Gy}$ doses of $\gamma$-irradiation, and the expression of SNCG was detected by western blotting at 24,48 and $72 \mathrm{~h}$ after radiation. (c and d) The viability of MDA-MB231 and MCF-7 cells was determined by an MTT assay. (e and f) The secreted SNCG was detected in the conditioned media from MDA-MB231 and MCF-7 cells using immunoblotting. The data represents the mean \pm S.D. of three independent experiments. ${ }^{\# \# P} P<0.001$ was compared with $24 \mathrm{~h} 0$ Gy group; while ${ }^{* * * P}<0.001$ and ${ }^{*} P<0.05$ were compared with the 0 Gy group in their seperate time frames. Significance was determined by one-way ANOVA followed by Tukey's multiple comparison tests. 

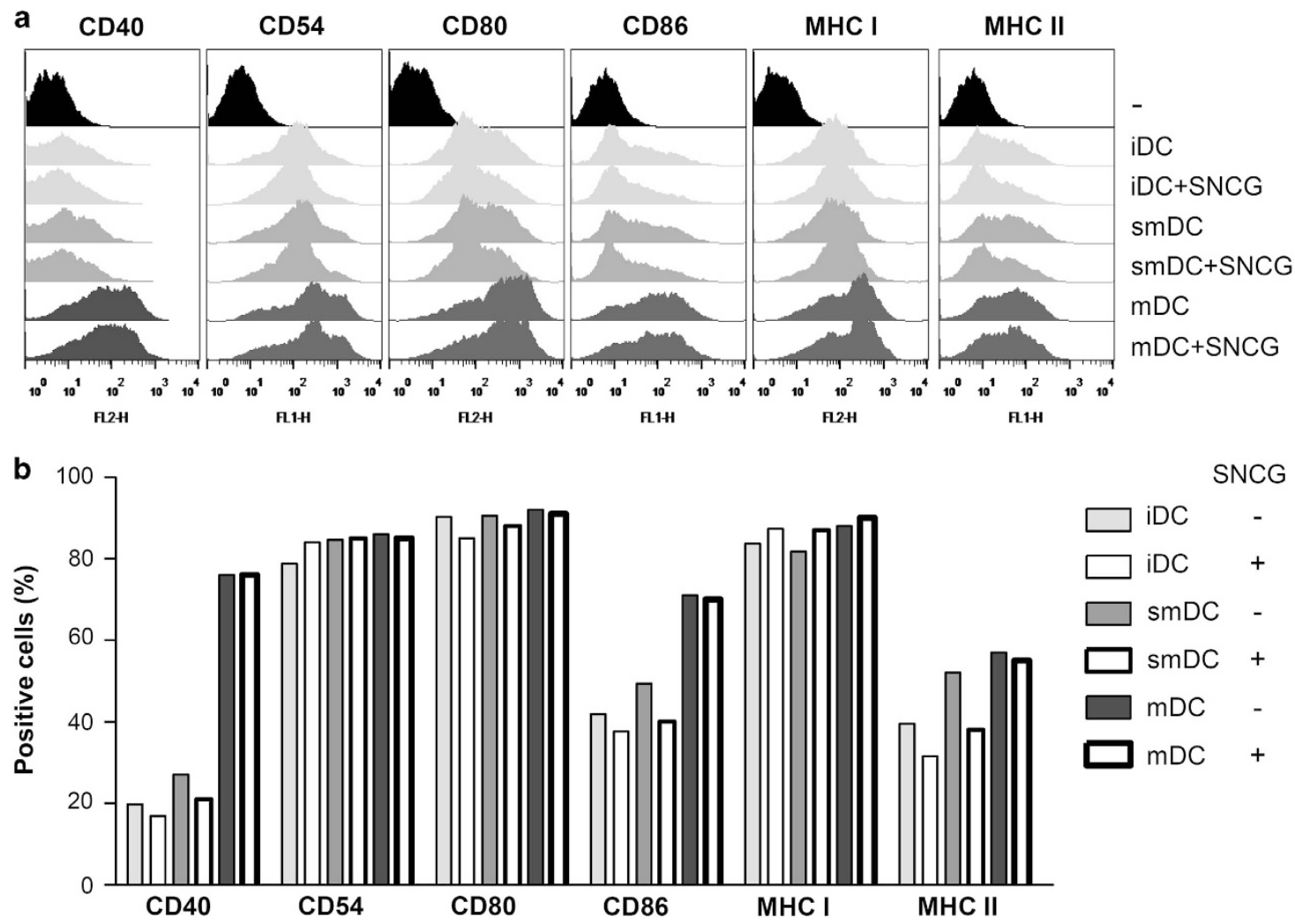

SNCG

Figure 2. SNCG altered the phenotypic changes of DCs. BMDCs were generated by culturing with $10 \mathrm{ng} / \mathrm{ml} \mathrm{GM-CSF}$ and $10 \mathrm{ng} / \mathrm{ml}$ IL-4 for 6 days. Then, the cells were treated with TNF- $a(10 \mathrm{ng} / \mathrm{ml})$ or LPS $(1 \mu \mathrm{g} / \mathrm{ml})$ in the absence or presence of SNCG $(1 \mu \mathrm{g} / \mathrm{ml})$ for $24 \mathrm{~h}$. (a) The antigen-presenting (MHC-I and -II) and representative co-stimulatory molecules of DCs, including CD40, CD80, and CD86, and the CD54 adhesion molecule, were evaluated by flow cytometry. (b) The above histogram data were analyzed and depicted as a bar graph of positively stained cells.

(iDC, smDC, and $\mathrm{mDC}$ ) in the presence or absence of SNCG. SNCG did not induce the apoptosis of bone marrow-derived DCs (BMDCs) during the GM-CSF/IL-4-mediated differentiation process (data not shown). As shown in Figure 2a, the expression of the co-stimulatory molecules CD40 and CD86 on mDCs were significantly increased compared with those on iDCs or smDCs. The antigen-presenting receptors $\mathrm{MHC}-\mathrm{I}$ and $-\mathrm{II}$, and an adhesion molecule, CD54, were also increased in mDCs. However, only minimal phenotypical changes between iDCs and smDCs were observed.

The expression of CD40, CD80, CD86, and MHC-II on smDCs or mDCs was downregulated when smDCs or mDCs were treated with SNCG (Figure 2b). These results indicate that SNCG impairs the antigen-presenting and T-cell-priming capacities of DCs by decreasing the expression of these surface molecules.

SNCG prevented the functional maturation of BMDCs

Next, we investigated the mRNA expression profile of several cytokines secreted from DC subsets in the presence or absence of SNCG to confirm the functional changes of the DC subsets. As shown in Figures $3 a$ and $f$, the inflammatory cytokines were significantly increased in mDCs compared with those secreted by iDCs or smDCs, whereas we did not observe differences in cytokine secretion between iDCs and smDCs. The expression levels of all of the above-mentioned cytokines were significantly decreased in SNCG-treated mDCs compared with mDCs without SNCG. Furthermore, SNCG-treated mDCs produced a slightly reduced amount of $\mathrm{IL}-12$ p70 and IL-23 compared with mDCs without SNCG, as confirmed by an ELISA assay (Figures $3 \mathrm{~g}$ and $\mathrm{h}$ ).
These results demonstrate that SNCG attenuated the production of pro-inflammatory cytokines of $\mathrm{mDCs}$.

SNCG-treated DCs generate anti-inflammatory and immunosuppressive T cells

To examine the effect of SNCG-treated DCs on T cells, different subsets of DCs in the presence of SNCG were mixed with CFSElabeled T cells for 5 days. The proliferation of $T$ cells incubated with SNCG-treated DCs was decreased compared with T cells incubated with DC subsets without SNCG (Figure 4a). Next, to investigate the differentiation of T-cell subsets, the population of $T$ cells producing IFN- $\gamma$, IL-4, or IL-17 was analyzed by flow cytometry following the $\mathrm{T}$ cell and $\mathrm{DC}$ coculture. smDCs mediate an increase in the population of IL-17-releasing $\mathrm{CD}^{+}{ }^{+} \mathrm{T}$ cells, whereas $\mathrm{mDC}$ s activate $\mathrm{CD} 4^{+} \mathrm{T}$ cells generating IFN- $\gamma$, IL-4, or IL-17 (Th1, Th2, and Th17). Whereas SNCG-treated iDCs increased the population of IL-17- or IL-4-producing T cells, smDCs and mDCs treated with SNCG appeared to reduce the population of $\mathrm{CD}^{+}$ $T$ cells secreting IFN- $\gamma$ or IL-17 cytokines. To determine the proportion of regulatory T cells (Tregs) in the coculture of T cells and SNCG-treated DCs, the total T cells were stained with antiCD4, anti-CD25, and anti-Foxp3. The Treg cell population in all SNCG-treated DC cocultures was increased compared with the cells cocultured with SNCG-untreated DC subsets (Figure 4b). These data clearly indicate that SNCG-treated DCs increase the immunosuppressive Treg cell population when cocultured with T cells.

As shown in Figure 4c, the production of IFN- $\gamma$ and IL-17 was significantly downregulated when $\mathrm{T}$ cells were cocultured with 
a

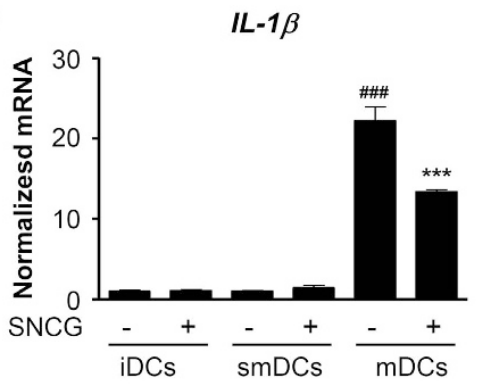

d

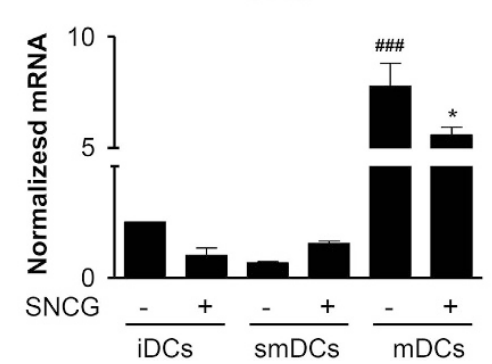

g

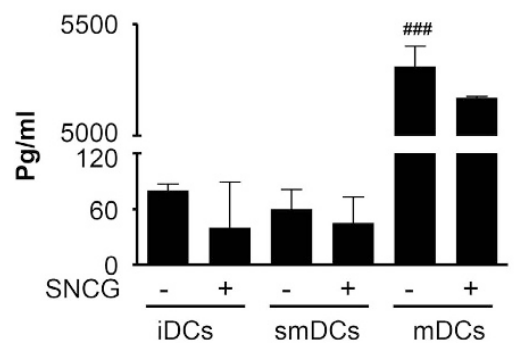

b

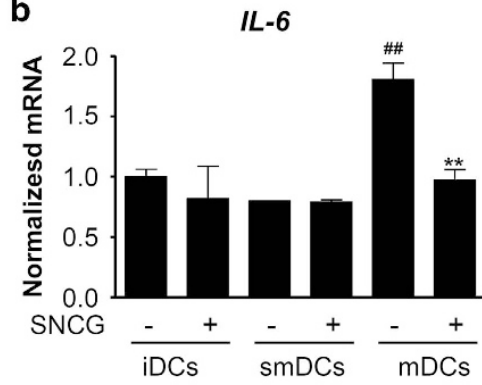

e

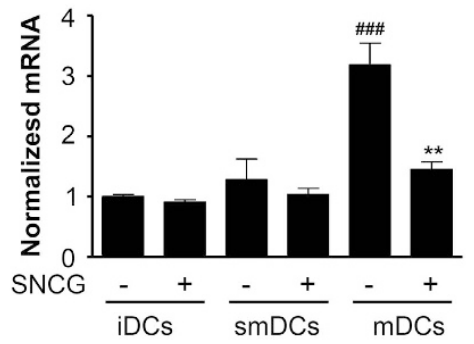

h

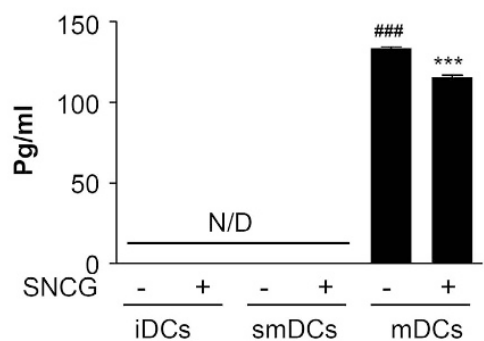

C

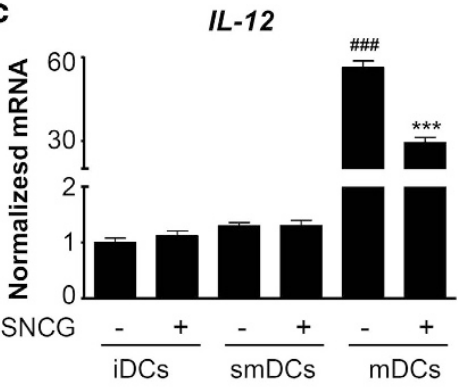

f

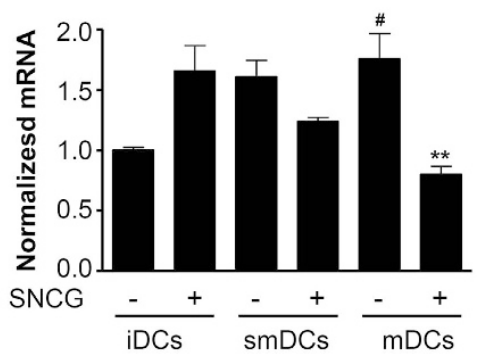

Figure 3. SNCG decreased immunostimulatory cytokines from mDCs. The iDCs, smDCs, or mDCs were treated with SNCG (1 $\mu \mathrm{g} / \mathrm{ml})$ for $24 \mathrm{~h}$. (a-f) The mRNA levels of IL-1 $\beta$, IL-6, IL-12, IL-23, IFN- $\gamma$, and TNF- $\alpha$ were normalized to the 18S mRNA level. (g and $\mathbf{h}$ ) The culture supernatants were evaluated for the production of IL- $12 \mathrm{p} 70$ and IL-23 by ELISA. The data represent the mean \pm S.D. of three independent experiments. ${ }^{\# \# \#} P<0.001,{ }^{\# \#} P<0.01$ and ${ }^{\#} P<0.05$ were compared with the imDC group; ${ }^{* *} P<0.001,{ }^{* *} P<0.01$ and ${ }^{*} P<0.05$ compared with the mDC group. Significance was determined by a one-way ANOVA followed by Tukey's multiple comparison tests.

SNCG-treated mDCs; in contrast, IL-4 was markedly upregulated. Furthermore, a representative immunosuppressive cytokine, TGF$\beta$, was also significantly increased in the supernatant of an SNCGtreated $\mathrm{mDC}$ (or smDC) and T-cell coculture. Taken together, SNCG-treated DCs induced Th2 immunity, consequently decreasing inflammatory cytokines and inhibiting antitumor immunity.

\section{Irradiated tumor cells inhibit DC activation}

Because $4 \mathrm{~T} 1$ is a murine mammary tumor cell line, we first investigated whether irradiated $4 \mathrm{~T} 1$ cells also release SNCG. As shown in Figure 5a, the SNCG concentration was increased in the conditioned medium of irradiated $4 \mathrm{~T} 1$ cells, similar to the results of Figures 1e and f. Next, to confirm whether soluble factors released by irradiated breast cancer cells were involved in the immunosuppressive activity of DCs, iDCs were separated from irradiated $4 \mathrm{~T} 1$ cells by Transwell system with a membrane pore size of $0.4 \mu \mathrm{M}$, which enables only soluble factors to diffuse. The 4T1 tumor cells did not further increase the maturation marker expression of $\mathrm{mDCs}$, whereas the antigen-presenting molecules MHC-I and MHC-II and the co-stimulatory molecules CD80 and CD86 were markedly reduced on DCs stimulated by irradiated 4T1 cells (Figure 5b). In addition, the IL-12 and TNF- $a$ mRNA expression from $\mathrm{mDCs}$ stimulated with irradiated $4 \mathrm{~T} 1$ cells was significantly decreased compared with non-treated mDCs or mDCs stimulated with non-irradiated 4T1 cells, similar to those of SNCG-treated DCs (Figure $5 \mathrm{c}$ ). Taken together, these results indicate that irradiated breast cancer cells can release several factors containing SNCG, thus impairing DC maturation via the downregulation of surface maturation markers and immunostimulatory cytokines.

\section{DISCUSSION}

DCs have a vital role as professional APCs that are able to activate naive $T$ cells and initiate $T$-cell responses, acting as messengers between the innate and adaptive immune systems. ${ }^{30}$ Therefore, many researchers have been highly interested in regulating DC activity and exploring DCs as therapeutic targets for treating various inflammatory and immunosuppressive disorders. ${ }^{31} \mathrm{RT}$ has traditionally been recognized as cytotoxic and immunosuppressive. Recently, substantial evidence has prompted the recharacterization of radiation as immunomodulatory rather than immunosuppressive. Thus, there have been many efforts to investigate the integration of RT in immune-based therapies. RT enhances the expression of tumor-associated antigens and secret immuno-activating danger signals, such as high-mobility group protein B1, heat-shock proteins, calreticulin, ATPs, and hepatoma- 
a iDC
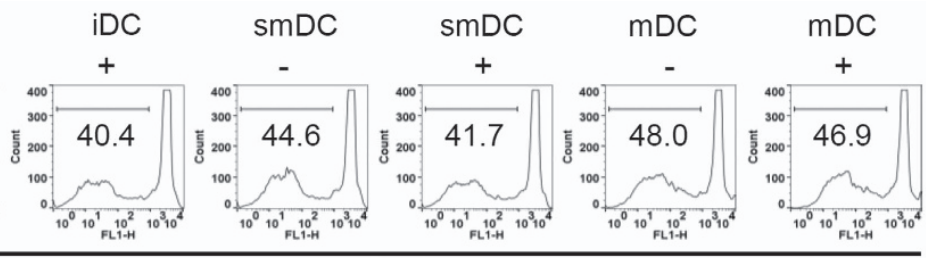

CFSE

b
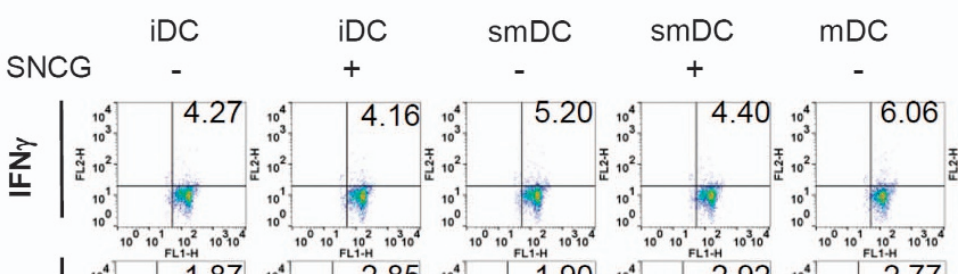

$\mathrm{mDC}$
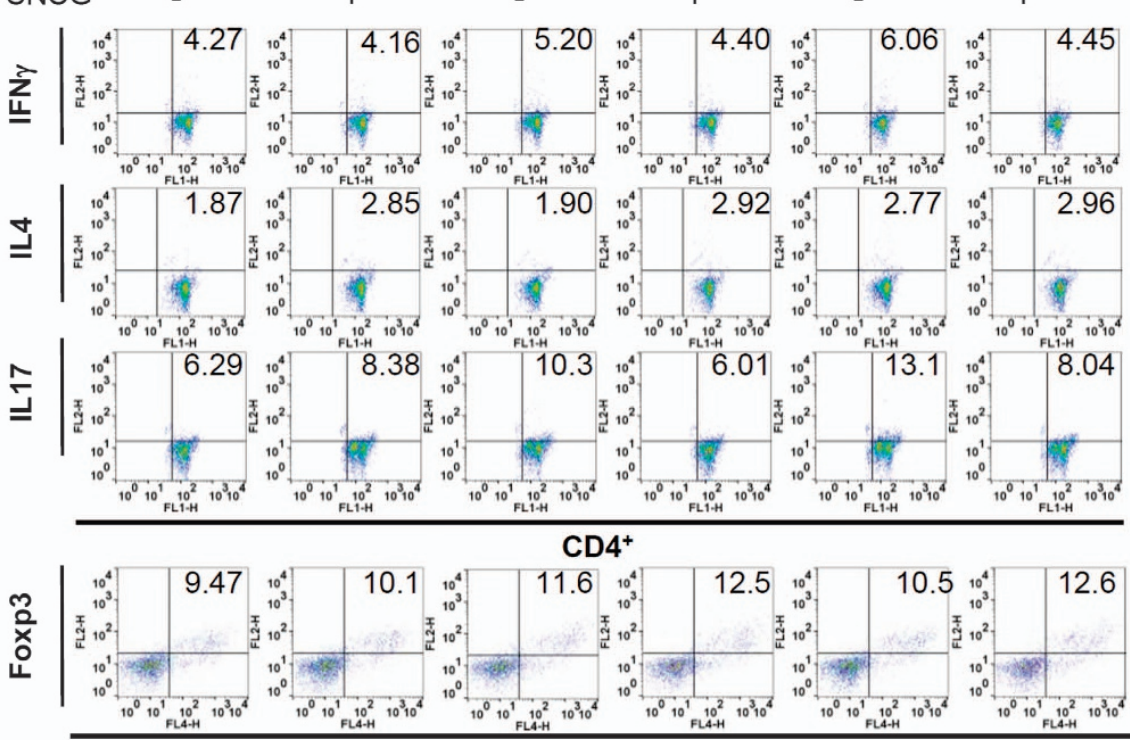

$\mathrm{CD}^{+}$

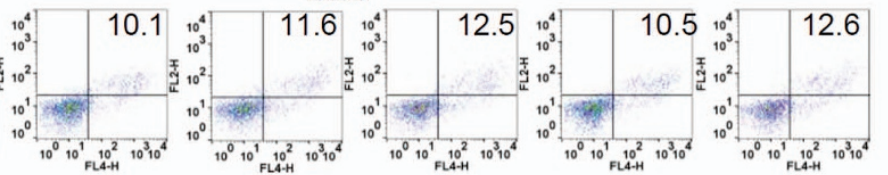

$\mathrm{CD}^{+}{ }^{+} \mathrm{CD} 25^{+}$
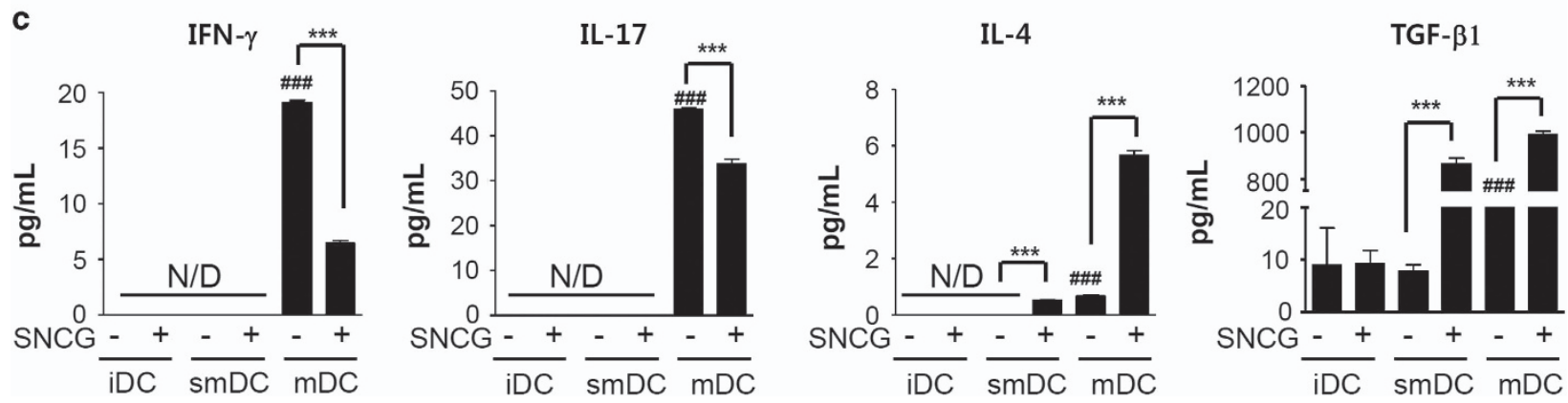

Figure 4. SNCG exhibits an immunosuppressive effect on DCs cocultured with $\mathrm{CD}^{+} \mathrm{T}$ cells. Spleens were isolated from 6- to 8-week-old $\mathrm{BALB} / \mathrm{c}$ mice, and CD4 ${ }^{+}$T cells were isolated using a pluriBead KIT (pluriSelect, Deutscher PI). (a) TNF- $a(10 \mathrm{ng} / \mathrm{ml}) \mathrm{or} \mathrm{LPS}(1 \mu \mathrm{g} / \mathrm{ml}) \mathrm{stimulated}$ DCs were treated with SNCG $(1 \mu \mathrm{g} / \mathrm{ml})$ and cocultured with CFSE-labeled CD4 ${ }^{+}$T cells $(1: 10)$ in 96 -well round-bottom plates for 5 days. The proliferation of the T cells was determined by flow cytometry. Representative data are shown as histograms. (b) The differentiated DCs in the presence or absence of SNCG were cultured with T cells $(1: 10)$ in six-well plates for 5 days, and then the populations of IFN- $\gamma-$, IL-4-, and IL-17secreting $\mathrm{CD}^{+}{ }^{+}$T cells, as well as $\mathrm{CD} 4^{+} \mathrm{CD} 25^{+} \mathrm{Foxp}^{+}$Treg cells, were determined by flow cytometry. The number in each panel indicates the percentage of double-positive cells. One of three similar results is shown. (c) The supernatants from coculturing DCs and T cells were evaluated for IFN- $\gamma$, IL-4, IL-17, and TGF- $\beta$ production by ELISA. The data represents the mean \pm S.D. of three independent experiments.

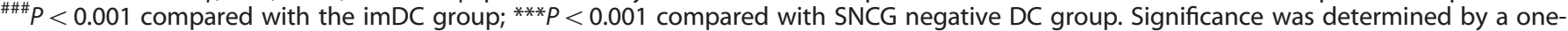
way ANOVA followed by Tukey's multiple comparison tests.

derived growth factor; thus, tumors can be easily detected by the immune system. ${ }^{32}$ Given our previous findings that SNCG was increased and released by irradiated breast cancer cells, we considered the possibility of SNCG as a DAMP, and thus investigated the effect of SNCG on the phenotypical and functional alteration of murine DCs.

Upon exposure to SNCG, TNF- $a$ - or LPS-stimulated smDCs or mDCs reduced their expression of several surface molecules that contribute to co-stimulation and antigen presentation to $T$ cells. In addition, $\mathrm{mDC}$ in the presence of SNCG significantly reduced the production of the inflammatory cytokines IL-1 $\beta$, IL-6, IL-12, IL-23, IFN- $\gamma$, and TNF- $a$. Although smDCs have been reported to induce Treg cells and reduce the levels of pro-inflammatory cytokine expression, smDCs might be inconsistent either in the upregulation of phenotypic maturation ligands or in the secretion of cytokines depending on the experimental conditions, and thus it is difficult to distinguish them from $\mathrm{mDCs}$ in this study. Coculture with SNCG-treated DCs downregulated T-cell proliferation and 
a 4T1
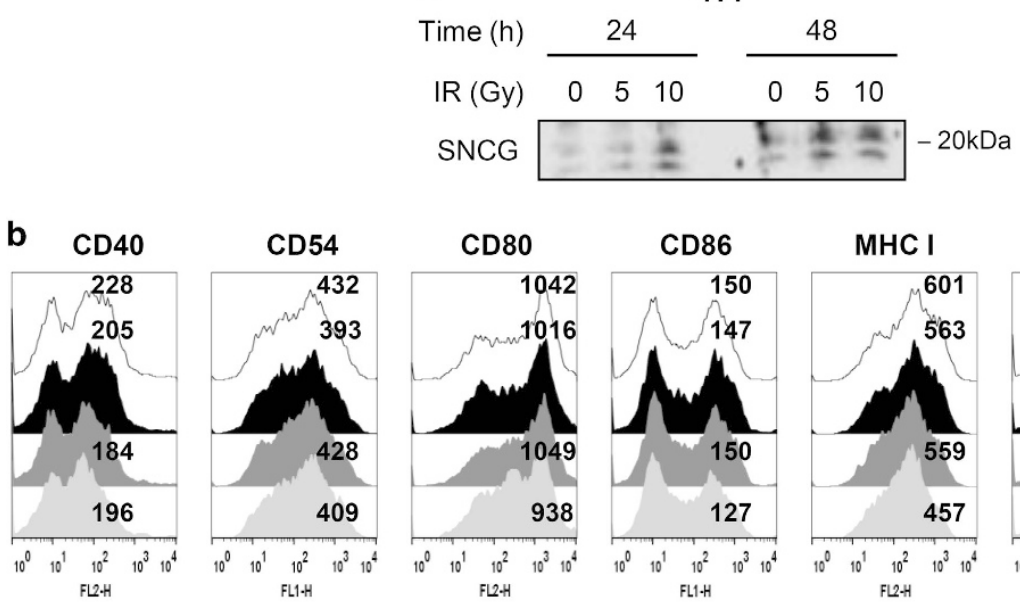

\section{MHC II}

IL-12

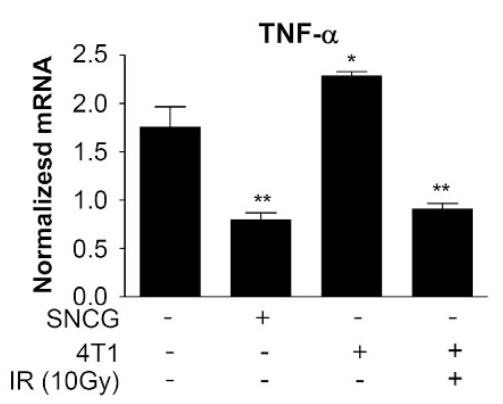

Figure 5. Irradiated tumor cells decreased DC maturation and activation. (a) The secreted SNCG was detected in the conditioned media from murine mammary 4T1 tumor cells using immunoblotting. (b) The mDCs $\left(1 \times 10^{6}\right.$ cells) were stimulated with SNCG $(1 \mu \mathrm{g} / \mathrm{ml})$ or irradiated $4 \mathrm{~T} 1$ murine breast carcinoma cells ( $\left.10 \mathrm{~Gy}, 2 \times 10^{5} \mathrm{cells}\right)$ for $48 \mathrm{~h}$ in a Transwell system. The surface maturation markers of the DCs were determined by FACS analysis. (c) The expression of IL-12 and TNF-a mRNAs isolated from DCs cocultured with SNCG or irradiated 4T1 tumor cells was investigated by real-time reverse transcription PCR and was normalized to $18 \mathrm{~S}$ mRNA. The data represents the mean \pm S.D. of three independent experiments. ${ }^{* *} P<0.001,{ }^{* *} P<0.01$ and ${ }^{*} P<0.05$ compared with the mDC group. Significance was determined by a one-way ANOVA followed by Tukey's multiple comparison tests.

altered the T-cell cytokine production profile, reducing proinflammatory cytokine IFN- $\gamma$ and IL-17 secretion and inducing the anti-inflammatory cytokines IL-4 and TGF- $\beta$. IR has been shown to release TGF- $\beta$ in vitro and in vivo. Whereas TGF- $\beta$ leads to growth inhibition and apoptosis, and serves as a tumor suppressor gene in normal tissues, TGF- $\beta$ expression is often increased and can be involved in some oncogene-like function in many tumors. We found that SNCG can significantly enhance TGF- $\beta$ production by $\mathrm{smDC}$ and $\mathrm{mDC}$. Owing to limitations in our ability to evaluate the in vivo quantitative and qualitative DC activation in the tumor microenvironment, we further investigated whether the soluble secretory factors from irradiated tumor cells may actually affect DC maturation, similar to SNCG. Similarly, irradiated tumor cells inhibited the activation of LPS-stimulated DCs through a decrease in surface maturation ligands and inflammatory IL-12 and TNF- $a$ cytokine production. In summary, SNCG derived from RT-treated dying tumor cells may moderate the stimulation of DCs, similar to smDCs, with low expression of phenotypic maturation ligands and the induction of immunosuppressive cytokines, thereby rendering the DCs incapable of efficiently interacting with T cells or eliciting fully immunogenic responses.

ICD has been demonstrated to be a cascade in which dying tumor cells release immunogenic factors that are received and processed by DCs, which in turn present antigen to activated cytotoxic T lymphocytes. However, whether RT specifically and efficiently elicits ICD remains a critical research question. Whereas RT may be efficient at releasing tumor antigens, the immunosuppressive tumor microenvironment may hamper the development of therapeutically effective antitumor immune responses. ${ }^{33}$ Furthermore, the DAMP spectrum can change even for the same cancer cell line depending on the type of treatment; the optimal dosing, timing, and sequencing of RT or other stimuli must be further investigated. Moreover, the ability of DCs to prime $T$ cells could be influenced by the concentration of antigenic peptide-MHC complex per DC; a higher concentration allows for more rapid T-cell activation. ${ }^{34,35}$ Consistent with these findings, the DC subsets did not change under treatment with $5 \mu \mathrm{g} / \mathrm{ml}$. Because we did not investigate the effect of a broad range of concentration SNCG on DCs, it remains possible that a higher concentration of SNCG may inversely cause an activation of DCs. However, the single $10 \mathrm{~Gy}$ dose of radiation was sufficient to release SNCG from dying cancer cells and evoked an immunosuppressive response against tumors.

Despite the accumulation of emerging evidence, it still remains challenging to understand how, when, and to what extent this dynamic spectrum of DC activation drives tumor-specific antitumor immunity, particularly, in the context of anticancer therapy. In this respect, the pre-existing or therapy-generated tumor microenvironments, as well as the cross talk between dying cancer cells and DCs, mediated by soluble and vesicular factors, are crucial determinants of the DC maturation status and anticancer immune response. Furthermore, the complex interplay between the radiation dose and the effect on target tissue-associated factors and host immunity has yet to be consistently defined. Despite these limitations, our findings indicate that SNCG, which can be released from dying irradiated breast cancer cells, might be 
at least partially involved in the persistence of tumor resistance against RT, and modulation of SNCG may be a promising approach for anticancer therapy.

With emerging interest in studying the mechanisms of IRinduced ICD, it is necessary to find novel immunomodulators and analyze certain existing therapies for their potential to cause DC maturation irrespective of whether they induced ICD. This study also cautiously suggests the predictable response of DCs against radiation-induced dying cancer cells.

\section{MATERIALS AND METHODS}

\section{Mice}

Female BALB/c mice, 6-8 weeks of age, were purchased from Samtako Bio Korea (Osan, Korea). All animal experiments were conducted according to the Korean National Guidelines of Laboratory Animal Experiment based on the protocol approved by the Institutional Animal Care and Use Committee of the Korea Institute of Radiological and Medical Sciences (KIRAMS 13-056).

\section{Cell cultures and generation of BMDCs}

BMDCs were generated as previously described ${ }^{36-40}$ with some modifications. Briefly, bone marrow cells were harvested from the femur and tibia of the hind legs. Next, the cells were depleted of red blood cells (RBCs) with RBC lysis buffer (Lonza, Walkersville, MD, USA). The cells were cultured for 6 days in RPMI 1640 (Lonza) containing 10\% fetal bovine serum (Gibco, Grand Island, NY, USA), 10000 units $/ \mathrm{ml}$ penicillin (Gibco), $10 \mathrm{ng} / \mathrm{ml} \mathrm{rmGM-}$ CSF (JW CreaGene, Daegu, Korea) and $10 \mathrm{ng} / \mathrm{ml} \mathrm{rmlL-4} \mathrm{(JW} \mathrm{CreaGene,}$ Daegu, Korea). The culture medium was replaced every 2 days. After 7 days, DCs were incubated for $24 \mathrm{~h}$ with $10 \mathrm{ng} / \mathrm{ml}$ rmTNF- $a$ (PeproTech, Rocky Hill, NJ, USA) or $1 \mu \mathrm{g} / \mathrm{ml}$ LPS (Sigma-Aldrich, St. Louis, MO, USA) to generate smDCs or fully $\mathrm{mDCs}$, respectively. At the same time, $1 \mu \mathrm{g} / \mathrm{ml}$ rhSNCG (Acris, San Diego, CA, USA) was co-administered to differentiate the DCs to investigate the effect of SNCG. The purity of the BMDC population was assessed by flow cytometry after CD11c labeling ( $>90 \%$ for $\mathrm{CD} 11 \mathrm{c}^{+}$cells).

\section{Western blot analysis}

Cells $(1 \times 106$ cells per $\mathrm{ml})$ cultured in $100 \mathrm{~mm}$ plates (SPL Lifescience, Pocheon, Korea) were lysed with RIPA buffer $(50 \mathrm{mM}$ Tris- $\mathrm{HCl}(\mathrm{pH} 7.4)$, $150 \mathrm{mM} \mathrm{NaCl}, 1 \% \mathrm{NP}-40$, and $1 \%$ sodium deoxycholate, and containing $1 \mathrm{mM}$ EDTA) supplemented with protease inhibitors ( $1 \mathrm{mM} \mathrm{PMSF}, 1 \mu \mathrm{g} / \mathrm{ml}$ aprotinin, $1 \mathrm{mM} \mathrm{Na} \mathrm{VO}_{4}$ and $1 \mathrm{mM} \mathrm{NaF}$ ). Proteins from whole-cell lysates were separated on $8-15 \%$ SDS-polyacrylamide gels and transferred to nitrocellulose membranes (Bio-Rad, Berkeley, CA, USA). The membrane was blocked with $5 \%$ skimmed milk in Tris-buffered saline containing $0.1 \%$ Tween-20 (TBS-T) for $1 \mathrm{~h}$ and probed with anti-SNCG (Abcam, Cambridge Science Park, Cambridge, UK) or anti- $\beta$-actin antibodies (AbFrontier, Seoul, Korea) overnight at $4^{\circ} \mathrm{C}$. After multiple washes, the membranes were incubated with peroxidase-conjugated secondary antibodies (Thermo Scientific, Waltham, MA, USA), and immunoreactive bands were detected using enhanced chemiluminescence reagents according to the manufacturer's recommendations (GE Healthcare, Little Chalfont, UK). The experiments were repeated at least three times. The immunoreactive bands were semi-quantified using a densitometer (Bio-Rad) and normalized to the band intensity of $\beta$-actin as a loading control.

\section{Flow cytometry}

Immunostaining was performed as described previously. ${ }^{41}$ Briefly, after 10 min of incubation at $4{ }^{\circ} \mathrm{C}$ with $\mathrm{Fc}$ receptor blocker (BD Biosciences, San Joses, (A, USA), the cells were stained with the corresponding antibodies. The antibodies used for DC phenotyping were CD11C-PE, CD14FITC, CD40-PE, CD54-FITC, CD80-PE, CD86-FITC, H-2K[d]-PE, and I-A[d]-FITC; all these antibodies were purchased from BD Biosciences. For intracellular cytokine staining, the cells were incubated with brefeldin A (BD Biosciences) for $1 \mathrm{~h}$. The cells were stained with surface markers, such as CD4-FITC and CD25-APC (BD Biosciences). Then, the cells were permeabilized using Cytofix/Cytoperm reagents (BD Biosciences) and stained for intracellular markers as follows: IFN- $\gamma$-PE, IL-4-PE (BD Biosciences), IL-17A$P E$, and Foxp3-PE (eBioscience, San Diego, CA, USA). Stained cells were acquired using a BD FACSCanto II flow cytometer (BD Biosciences) and analyzed using the FlowJo software (v.10, Ashland, OR, USA).

\section{Measurement of cytokines}

Cell-free supernatants derived from DCs alone as well as coculture with DC and $T$ cells were harvested, and the cytokine levels were determined by ELISA. The amounts of IL-12p70, IFN- $\gamma$, IL-4 (BD Biosciences), IL-17A, TGF- $\beta$ (R\&D Systems, Minneapolis, MN, USA), or IL-23 (Invitrogen, Waltham, MA, USA) ELISA kits were evaluated according to the manufacturer's instructions.

\section{Real-time quantitative reverse transcription PCR}

Total RNA was isolated from DCs using TRIzol (Invitrogen Life Technologies, Waltham, MA, USA), and RNA was reverse transcribed using M-MLV Reverse Transcriptase (Enzynomics, Daejeon, Korea), Oligo dT (Enzynomics) and RNasin Ribonuclease Inhibitor (Promega, Fitchburg, WI, USA). The mRNA levels were assessed by real-time quantitative reverse transcription PCR using Maxima SYBR Green quantitative PCR Master Mix (Thermo Scientific) with a CFX96 Touch Real-Time PCR Detection System (Bio-Rad). Relative quantification of gene expression was performed using the $\Delta \Delta C_{t}$ method in CFX Manager software (Bio-Rad) using 185 ribosomal RNA as an internal reference. The primer pairs for the analyzed genes were supplied by Bioneer (Daejeon, Korea), and the sequences were as follows: IL-6 (N-4013); IL-1 $\beta$ (N-4009); TNF- $a$ (N-4015); 18 S forward 5'-CGAAAGCATTGC CAAGAAT-3', reverse 5'-AGTCGGCATCGTTATGG TC-3'; IL-12 forward 5'-CTCCTGTGGGAGAAGCAGAC-3', reverse 5'-CAGATAGCC CATCACCCTG-3'; IL-23 forward 5'-AATAATGTGCCCCGTATCCA-3', reverse 5'-AGGCTCCCCT TTGAAGATGT-3'; IFN- $\gamma$ forward 5'-GAGGTCAACAACCCACAGGT-3', reverse 5'-GGGACAATCTCTTCCCCACC-3'.

\section{Coculture of DCs and T cells}

DCs $\left(2 \times 10^{5}\right.$ cells per $\left.\mathrm{ml}\right)$ were cocultured with $\mathrm{CD}^{+} \mathrm{T}$ cells $\left(1 \times 10^{6}\right.$ cells per $\mathrm{ml}$ ), which were isolated from splenocytes obtained from naive BALB/C mice using a CD4 isolation kit (pluriSelect, Deutscher PI, Leipzig, Germany). The cells were cocultured in RPMI 1640 supplemented with 10\% FBS for $72 \mathrm{~h}$ at $37^{\circ} \mathrm{C}$ with $5 \% \mathrm{CO}_{2}$. To evaluate T-cell proliferation, isolated $\mathrm{CD}^{+}$ $\mathrm{T}$ cells were stained using a CellTrace CFSE Cell Proliferation Kit (Life Technologies, Waltham, MA, USA) and analyzed by flow cytometry. The DCs $\left(2 \times 10^{5}\right.$ cells per $\left.\mathrm{ml}\right)$ were transferred to a 96 -well plate and then cocultured with CFSE-labeled T cells $\left(2 \times 10^{6}\right.$ cells per ml) for 5 days at $37^{\circ} \mathrm{C}$ with $5 \% \mathrm{CO}_{2}$.

\section{DC sensitization with irradiated tumor cells}

To determine the effect of secretory molecules from irradiated tumor cells on DCs, 4T1 murine mammary carcinoma cells $\left(2 \times 10^{5}\right)$ were cocultured with DCs using a Transwell system. The LPS-stimulated mDCs $\left(1 \times 10^{6}\right)$ were seeded in 24-well plates. The 4T1 murine mammary carcinoma cells $\left(2 \times 10^{5}\right)$ were exposed with or without a $10 \mathrm{~Gy}$ dose of radiation and loaded in 0.4- $\mu \mathrm{m}$ pore size Transwell inserts on a 24-well cell culture plate (Corning Glass, Seoul, Korea). Control DCs were cultured using the same conditions but in the absence of $4 \mathrm{~T} 1$ cells.

\section{Statistical analysis}

Statistical analyses were performed using the GraphPad software, version 5 (GraphPad, La Jolla, CA, USA). The data are presented as mean \pm S.D. Significant differences between the groups were determined by analysis of variance and Tukey's post hoc test. $P$-values $<0.05$ were considered statistically significant.

\section{ACKNOWLEDGEMENTS}

This work was supported by the Korean Health Technology R\&D Project (grant HI11C1798) of the Ministry of Health and Welfare.

\section{COMPETING INTERESTS}

The authors declare no conflict of interest.

\section{REFERENCES}

1 Barnett GC, West CM, Dunning AM, Elliott RM, Coles CE, Pharoah PD et al. Normal tissue reactions to radiotherapy: towards tailoring treatment dose by genotype. Nat Rev Cancer 2009; 9: 134-142.

2 Begg AC, Stewart FA, Vens C. Strategies to improve radiotherapy with targeted drugs. Nat Rev Cancer 2011; 11: 239-253. 
3 Eriksson D, Stigbrand T. Radiation-induced cell death mechanisms. Tumour Biol 2010; 31: 363-372.

4 Buller S. Lasting attachments. Nursing Times 1989; 85: 36-37.

5 Ding $Y$, Yan Q, Ruan JW, Zhang YQ, Li WJ, Zeng $X$ et al. Bone marrow mesenchymal stem cells and electroacupuncture downregulate the inhibitor molecules and promote the axonal regeneration in the transected spinal cord of rats. Cell Transplant 2011; 20: 475-491.

6 Liu C, Lin J, Zhao L, Yang Y, Gao F, Li B et al. Gamma-ray irradiation impairs dendritic cell migration to CCL19 by down-regulation of CCR7 and induction of cell apoptosis. Int J Biol Sci 2011; 7: 168-179.

7 Ma Y, Kepp O, Ghiringhelli F, Apetoh L, Aymeric L, Locher C et al. Chemotherapy and radiotherapy: cryptic anticancer vaccines. Semin Immunol 2010; 22: 113-124.

8 Apetoh L, Ghiringhelli F, Tesniere A, Obeid M, Ortiz C, Criollo A et al Toll-like receptor 4-dependent contribution of the immune system to anticancer chemotherapy and radiotherapy. Nat Med 2007; 13: 1050-1059.

9 Kroemer G, Zitvogel L. Abscopal but desirable: the contribution of immune responses to the efficacy of radiotherapy. Oncoimmunology 2012; 1: 407-408.

10 King MH, Jung SY, Ahn J, Hwang SG, Woo HJ, Ah S et al. Quantitative proteomic analysis of single or fractionated radiation-induced proteins in human breast cancer MDA-MB-231 cells. Cell Biosci 2015; 5: 2.

11 Jakes R, Spillantini MG, Goedert M. Identification of two distinct synucleins from human brain. FEBS Lett 1994; 345: 27-32.

12 Giasson BI, Duda JE, Forman MS, Lee VM, Trojanowski JQ. Prominent perikaryal expression of alpha- and beta-synuclein in neurons of dorsal root ganglion and in medullary neurons. Exp Neurol 2001; 172: 354-362.

13 Li J, Henning Jensen P, Dahlstrom A. Differential localization of alpha-, beta- and gamma-synucleins in the rat CNS. Neuroscience 2002; 113: 463-478.

14 Lavedan C. The synuclein family. Genome Res 1998; 8: 871-880.

15 Kwon YJ, Lee SJ, Koh JS, Kim SH, Kim YJ, Park JH. Expression patterns of aurora kinase $B$, heat shock protein 47 , and periostin in esophageal squamous cell carcinoma. Oncol Res 2009; 18: 141-151.

16 Wu K, Weng Z, Tao Q, Lin G, Wu X, Qian H et al. Stage-specific expression of breast cancer-specific gene gamma-synuclein. Cancer Epidemiol Biomarkers Prev 2003; 12: $920-925$

17 Bruening W, Giasson BI, Klein-Szanto AJ, Lee VM, Trojanowski JQ, Godwin AK Synucleins are expressed in the majority of breast and ovarian carcinomas and in preneoplastic lesions of the ovary. Cancer 2000; 88: 2154-2163.

18 Li Z, Sclabas GM, Peng B, Hess KR, Abbruzzese JL, Evans DB et al. Overexpression of synuclein-gamma in pancreatic adenocarcinoma. Cancer 2004; 101: 58-65.

19 Ye Q, Feng B, Peng YF, Chen XH, Cai Q, Yu BQ et al. Expression of gammasynuclein in colorectal cancer tissues and its role on colorectal cancer cell line HCT116. World J Gastroenterol 2009; 15: 5035-5043.

$20 \mathrm{Ji} \mathrm{H}$, Liu YE, Jia T, Wang M, Liu J, Xiao G et al. Identification of a breast cancer-specific gene, BCSG1, by direct differential cDNA sequencing. Cancer Res 1997; 57: 759-764.

21 Jia T, Liu YE, Liu J, Shi YE. Stimulation of breast cancer invasion and metastasis by synuclein gamma. Cancer Res 1999; 59: 742-747.

22 Lavedan C, Leroy E, Dehejia A, Buchholtz S, Dutra A, Nussbaum RL et al. Identification, localization and characterization of the human gamma-synuclein gene. Human Genet 1998; 103: 106-112.

23 Bayry J, Thirion M, Delignat S, Misra N, Lacroix-Desmazes S, Kazatchkine MD et al. Dendritic cells and autoimmunity. Autoimmun Rev 2004; 3: 183-187.

24 Cools N, Ponsaerts P, Van Tendeloo VF, Berneman ZN. Balancing between immunity and tolerance: an interplay between dendritic cells, regulatory $T$ cells, and effector T cells. J Leukoc Biol 2007; 82: 1365-1374.
25 Gabrilovich DI, Cheng P, Fan Y, Yu B, Nikitina E, Sirotkin A et al. H1(0) histone and differentiation of dendritic cells. A molecular target for tumor-derived factors. $J$ Leukoc Biol 2002; 72: 285-296.

26 Enk $A$ H, Jonuleit $H$, Saloga J, Knop J. Dendritic cells as mediators of tumor-induced tolerance in metastatic melanoma. Int J Cancer 1997; 73: 309-316.

27 Foster BJ, Wiegand RA, Pugh S, LoRusso PM, Rake J, Corbett TH. Pharmacokinetic studies in mice of two new thioxanthenones (183577 and 232759) that showed preferential solid tumor activity. Clin Cancer Res 1997; 3: 2047-2053.

28 Roses RE, Datta J, Czerniecki BJ. Radiation as immunomodulator: implications for dendritic cell-based immunotherapy. Radiat Res 2014; 182: 211-218.

29 Langenkamp A, Messi M, Lanzavecchia A, Sallusto F. Kinetics of dendritic cell activation: impact on priming of $\mathrm{TH} 1, \mathrm{TH} 2$ and nonpolarized T cells. Nat Immunol 2000; 1: 311-316.

30 Coquerelle $C$, Moser $M$. DC subsets in positive and negative regulation of immunity. Immunol Rev 2010; 234: 317-334.

31 Figdor CG, de Vries IJ, Lesterhuis WJ, Melief CJ. Dendritic cell immunotherapy: mapping the way. Nat Med 2004; 10: 475-480.

32 Krysko DV, Garg AD, Kaczmarek A, Krysko O, Agostinis P, Vandenabeele P. Immunogenic cell death and DAMPs in cancer therapy. Nat Rev Cancer 2012; 12 860-875.

33 Schreiber RD, Old LJ, Smyth MJ. Cancer immunoediting: integrating immunity's roles in cancer suppression and promotion. Science 2011; 331: 1565-1570.

34 Henrickson SE, Perro M, Loughhead SM, Senman B, Stutte S, Quigley M et al. Antigen availability determines CD8(+) $\mathrm{T}$ cell-dendritic cell interaction kinetics and memory fate decisions. Immunity 2013; 39: 496-507.

35 Henrickson SE, Mempel TR, Mazo IB, Liu B, Artyomov MN, Zheng H et al. T cell sensing of antigen dose governs interactive behavior with dendritic cells and sets a threshold for T cell activation. Nat Immunol 2008; 9: 282-291.

36 Inaba K, Inaba M, Romani N, Aya H, Deguchi M, Ikehara S et al. Generation of large numbers of dendritic cells from mouse bone marrow cultures supplemented with granulocyte/macrophage colony-stimulating factor. J Exp Med 1992; 176: 1693-1702.

37 Lutz MB, Kukutsch N, Ogilvie AL, Rossner S, Koch F, Romani N et al. An advanced culture method for generating large quantities of highly pure dendritic cells from mouse bone marrow. J Immunol Methods 1999; 223: 77-92.

38 MacDonald AS, Pearce EJ. Cutting edge: polarized Th cell response induction by transferred antigen-pulsed dendritic cells is dependent on IL-4 or IL-12 production by recipient cells. J Immunol 2002; 168: 3127-3130.

39 Reis e Sousa C. Dendritic cells in a mature age. Nat Rev Immunol 2006; 6: 476-483.

40 Yang S, Li W, Liu W, Gao C, Zhou B, Li S et al. IL-10 gene modified dendritic cells induced antigen-specific tolerance in experimental autoimmune myocarditis. Clin Immunol 2006; 121: 63-73.

41 Karlsen M, Hovden AO, Vogelsang P, Tysnes BB, Appel S. Bromelain treatment leads to maturation of monocyte-derived dendritic cells but cannot replace PGE2 in a cocktail of IL-1beta, IL-6, TNF-alpha and PGE2. Scand J Immunol 2011; 74: $135-143$.

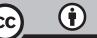

This work is licensed under a Creative Commons Attribution 4.0 International License. The images or other third party material in this article are included in the article's Creative Commons license, unless indicated otherwise in the credit line; if the material is not included under the Creative Commons license, users will need to obtain permission from the license holder to reproduce the material. To view a copy of this license, visit http://creativecommons.org/licenses/ by/4.0/ 